\title{
A utilização de sentenças aditivas pelo STF através da interpretação conforme à Constituição: um estudo a partir da
}

\section{ADPF 54}

\section{André Luiz Maluf Chaves}

Subprocurador Geral do Município de Teresópolis. Bacharel em Direito pela Universidade Federal Fluminense (UFF). E-mail: andremaluf@id.uff.br

\section{Matheus Meott Silvestre}

Doutorando em Direito Público pela Universidade do Estado do Rio de Janeiro (UERJ). Mestre em Direito Constitucional pela Universidade Federal Fluminense (UFF). E-mail: meottms@gmail.com

\section{Resumo}

Em tempos de crises políticas e judicialização, a doutrina e a jurisprudência têm se deparado com questões delicadas envolvendo a hermenêutica constitucional. Diante de tal quadro, o papel desempenhado pelo Supremo Tribunal Federal ganha relevância. Isso ocorre, sobretudo, porque, em inúmeros casos, a solução constitucionalmente adequada não se mostra evidente, o que exige da Corte um esforço teórico maior na utilização da técnica decisória correta. Nessa linha, o presente artigo busca desmistificar alguns dogmas estabelecidos em torno da interpretação conforme à Constituição. Para tanto, nos valemos da técnica de decisão conhecida como sentença manipulativa aditiva, que vem ganhando força no Brasil, sobretudo pela atuação da Corte Costituzionale italiana. Apesar disso, buscamos demonstrar que o STF não possui um entendimento consolidado sobre sua utilização, muitas vezes fazendo confusão entre os dois institutos.

\section{Palavras-chave}

Sentenças aditivas; Interpretação conforme à Constituição; ADPF 54; Corte Costituzionale; Supremo Tribunal Federal

\section{Additive decisions by STF interpretation according to the Constitution: A study about the ADPF 54 case}

\author{
Revista Publicum \\ Rio de Janeiro, v. 3, n. 2, 2017, p. 54-77 \\ http://www.e-publicacoes.uerj.br/index.php/publicum \\ DOI: 10.12957/publicum.2017.28650
}




\begin{abstract}
In times of political crisis and judicialization, doctrine and jurisprudence have increasingly come up against sensitive issues surrounding constitutional hermeneutics. Faced with such a framework, the role played by the Federal Supreme Court becomes more relevant. This is because, in many cases, a constitutionally adequate solution is not evident, which requires a greater theoretical effort by the Court in the correct decision-making technique. In this line, the present article seeks to demystify some dogmas established around the interpretation according to the Constitution. For that, we use the decision technique known as the additive manipulative decision, which has been gaining strength in Brazil, especially by the work of the Italian Constitutional Court. Despite this, we have tried to demonstrate that the STF does not have a consolidated understanding of its own use, often causing confusion between the two institutes.
\end{abstract}

\title{
Keywords
}

Additive decisions; interpretation according to the Constitution; ADPF 54; Italian Constitutional Court; Brazilian Federal Supreme Court.

\section{Sumário}

Introdução; 1. As sentenças manipulativas aditivas. 2. Uma análise crítica da interpretação conforme à Constituição. 3. A utilização de sentenças aditivas pelo STF através de interpretação conforme à Constituição: um estudo da ADPF 54 (aborto de fetos anencéfalos). 4. Críticas à utilização de sentenças aditivas pelo STF e a necessidade de evolução do paradigma kelseniano. Conclusão.

\section{Introdução}

Em tempos de ativismo judicial e judicialização de questões políticas a doutrina e a jurisprudência têm se deparado com questões delicadas envolvendo a hermenêutica constitucional. Somado a isso, crises políticas e econômicas influenciam negativamente o equilíbrio entre os Poderes, de modo que uma fagulha em momento inoportuno é capaz de ensejar sérias consequências em termos institucionais.

Recentemente temos acompanhado debates, extremamente relevantes para o futuro do país, que envolvem assuntos polêmicos, como redução da maioridade penal, terceirização, financiamento de campanhas, obrigatoriedade do voto, Estatuto da Magistratura, descriminalização do consumo de maconha, mudanças no sistema recursal penal, dentre outros.

Sob tal ótica, o Supremo Tribunal Federal desempenha importante papel como guardião da Constituição e garantidor dos direitos fundamentais, sobretudo quando se fala em minorias. Podemos afirmar que tal função é desempenhada na sua máxima potência quando a Corte exerce o controle de constitucionalidade, seja através de Recurso Extraordinário, seja através das ações de controle concentrado. 
Com relação a estas últimas, questão de suma importância parece estar despertando o interesse da doutrina nos últimos tempos: qual técnica de decisão a ser utilizada em casos onde a solução constitucionalmente adequada não é evidente? A resposta para tal indagação está longe de ser simples. Por isso, a valorização do estudo hermenêutico das decisões judiciais parece ganhar fôlego diante de casos emblemáticos como aborto de fetos anencéfalos, união homoafetiva, demarcação de terras indígenas, direito de greve dos servidores públicos, etc.

Ante o exposto, a proposta do presente trabalho é analisar criticamente, à luz da jurisprudência do Supremo e da Corte Costituzionale italiana, duas técnicas de decisão: a interpretação conforme à Constituição e a sentença manipulativa aditiva.

Inicialmente, buscaremos esclarecer quais as características principais de ambas as técnicas de decisão. Em seguida, teceremos alguns comentários críticos em relação à utilização da interpretação conforme à Constituição pelo STF, objetivando demonstrar que ocorre uma confusão entre tal instituto e as sentenças aditivas. Utilizaremos, para tanto, o teor dos votos proferidos no julgamento da ADPF 54 que trata do aborto de fétos anencéfalos. Por fim, será feita uma breve incursão na literatura a respeito do tema no Brasil e a apresentação das principais questões que a temática suscita.

\section{As sentenças manipulativas aditivas}

As sentenças aditivas têm íntima relação com a ocorrência do fenômeno da omissão inconstitucional. Hodiernamente, a doutrina é uníssona no sentido de que é possível violar a Constituição praticando atos contrários a ela, seja através de uma ação, seja através de uma omissão (BARROSO, 2012, p. 53). Todavia, inicialmente, a jurisdição constitucional não foi concebida para resolver os problemas relativos às Omissões dos Poderes Representativos, mas somente para deixar de aplicar a regra ao caso concreto (Marbury v. Madison), sobretudo pelo temor da atuação dos magistrados (SANCHEZ, apud ISRAEL, p. 27) ${ }^{1}$. Posteriormente, inovou-se com a teoria kelseniana de legislador negativo, que não se sustentou diante das Constituições de cunho programático, analítico e inúmeros conceitos indeterminados, sendo potencializado pela inércia dos Poderes Representativos.

\footnotetext{
1 No original: “El dogma de la soberenía de la ley, que nunca gozó de gran tradición ni fuerza, cedió fácilmente a la supremacía de la Constituición. De manera adicional, las negativas vicisitudes del regimen parlamentario italiano han golpeado con más fuerza que ninguna outra democracia occidental el prestigio del legislador, cuya actividad ha estado marcada por la partitocracia y la inercia. [...] la jurisdicción constitucional nahá llegado a engendrar en Italia en ningún nomento el típico temor al 'gobierno de los jueces'; el Tribunal Constitucional italiano ha conquistado um papel estelar em la realidad democrática em que se mueve; a diferencia de otros Tribunales Constitucionales europeos, 'no se preocupa em disimular su poder creador': reconoce sin embagos a su jurisprudência como fuente de Derecho; tiende a desligarse con facilidad de reglas de interpretación fi jas y entiende la interpretación constitucional desde el realismo jurídico, sobre métodos ampliamente deductivos, en particular el histórico-evolutivo, es decir, la entiende como acto de voluntad y no como acto de conocimiento, concepción esta típica del positivismo jurídico, como es sabido."
} 
Mais adiante, o direito alemão desenvolveu o apelo ao legislador "Appell-Entscheidungen" (expressão original) e a interpretação conforme à Constituição. Na Itália, desenvolveram-se as sentenças manipulativas e, em Portugal, a Ação Direta de Inconstitucionalidade por Omissão e a possibilidade de indenização no caso de omissão (DOUGLAS, ARAÚJO, CHAVES, 2016, p. 183).

Brasil e Equador inovaram no sistema de combate às omissões inconstitucionais, respectivamente, por meio do Mandado de Injunção, previsto no artigo 5으, LXXI, da Constituição Federal e regulamentado pela Lei 13.300/16, e através da atuação da Corte Constitucional como legislador suplente e precário (MALUF; SILVESTRE, 2015).

A sentença aditiva (clássica ou tradicional) surge diante da omissão do Parlamento italiano em conformar a antiga ordem infraconstitucional fascista com a Constituição de 1947, haja vista a permanência dessa legislação pré-constitucional mesmo depois da entrada em vigor da nova Carta (CAMPOS, 2011, p. 25). Ademais, por não dispor de instrumentos constitucionais específicos para tratar da inconstitucionalidade por omissão (como a Ação Direta de Inconstitucionalidade por Omissão e o Mandado de Injunção), a Corte acabou criando tal técnica de decisão. Logo, através dela, buscou remover, de forma menos traumática à estrutura do ordenamento, a legislação residual fascista (ANGELONE, 2006, p. 563).

Além disso, a prolação de sentenças aditivas tem o objetivo de resguardar a própria presunção de constitucionalidade das leis, de modo a evitar uma declaração de inconstitucionalidade que possa vir a gerar uma perigosa lacuna no ordenamento em caso de uma norma deficiente (ANGELONE, 2006, p. 566). ${ }^{2}$ Roberto Romboli esclarece a questão:

\begin{abstract}
A jurisprudência constitucional, sempre com a finalidade de evitar a rígida opção de declaração de inconstitucionalidade ou falta de fundamento, elaborou, ademais, as chamadas sentenças manipulativas para que a Corte possa modificar ou integrar as disposições submetidas a sua jurisdição de um modo que estas passem pelo juízo constitucional com um alcance normativo e um conteúdo diferente do originário. No âmbito das sentenças manipulativas, deve-se fazer uma consideração, a diferenciação entre as decisões aditivas e substitutivas. As primeiras fazem referência àquele tipo de decisão onde a Corte declara inconstitucional certa disposição por omitir algo (inconstitucional na parte que não traz previsão). (1999, p. 14) ${ }^{3}$
\end{abstract}

\footnotetext{
${ }^{2}$ Como visto, tal argumento se reforça pela possibilidade de o juízo a quo dar interpretação conforme com o objetivo de salvar a constitucionalidade da lei.

${ }^{3}$ Tradução nossa. No original: "La jurisprudência constitucional, siempre com la finalidad de evitar la rígida alternativa entre declaracíon de falta de fundamento o de inconstitucionalidad, há elaborado, además, las denominadas sentencias manipulativas por las que la Corte procede a modificar o integrar las disposiciones sometidas a su enjuiciamento de un modo que éstas salgan del judicio constitucional con un alcance normativo y un contenido diferente al originario. En el ambito de las decisiones manipulativas debe añadirse una ulterior consideración, la diferenciacion entre decisiones aditivas e sustitutivas. Com las primeras se hace referencia a aquel tipo de decision con la que la Corte declara inconstitucional una cierta disposicion por omitir algo (-en la parte en la que no prevé-)."
}

Revista Publicum

Rio de Janeiro, v. 3, n. 2, 2017, p. 54-77

http://www.e-publicacoes.uerj.br/index.php/publicum

DOI: $10.12957 /$ publicum.2017.28650 
As sentenças aditivas, como espécie do gênero manipulativas, são aquelas que reconhecem a falta de elemento normativo necessário para que a norma em julgamento esteja de acordo com a Constituição e que acrescentam a essa norma o elemento ausente, que pode ser outra norma ou princípio constitucional do ordenamento jurídico:

Não há criação livre de direito novo, mas uma dedução de conteúdo normativo dos princípios presentes no ordenamento jurídico, e destacadamente da sua norma fundamental: a manipulação, em outros termos, ocorre (e somente pode ocorrer) a "rime obbligate". (BELLOCCI, M.; GIOVANETTI, 2010, p.19)

Isso significa que a norma tida como inconstitucional é complementada com o objetivo de sanar o vício de inconstitucionalidade. Por meio das decisões/sentenças aditivas, a Corte declara inconstitucional uma certa disposição em razão de omitir algo que seria necessário para ser compatível com a Constituição. Logo, com vistas a tornar a norma compatível ao Texto Maior e preservar sua presunção júris tantum de constitucionalidade, o Tribunal adiciona conteúdo normativo ao dispositivo (MALFATI; PANIZZA; ROMBOLI, 2013, p. 136).

A sentença aditiva pode ser utilizada quando restar patente uma inconstitucionalidade por omissão, com o objetivo de assegurar o exercício de direitos previstos na Constituição ${ }^{5}$, através de regras ou princípios, ou para preservar a lei quando esta necessitar de uma adição ao seu conteúdo para continuar em vigor. Logo, utilizando uma sentença aditiva, a Corte prolata decisão de cunho normativo apta a concretizar o que já constava no texto constitucional de forma obrigatória (a rime obbligate).

Vale ressaltar que o direito alemão, por exemplo, possui uma posição restrita acerca do instituto das sentenças aditivas por entender que estas violam a liberdade e discricionariedade do legislador. Todavia, quando a Constituição expressamente impõe uma determinada forma de correção para uma desigualdade presente no caso concreto, a Corte admite decisões manipulativas (BOSELLI, 2013, p. 106). Prova disso é a decisão BVerfGE 39, I, de 1975, relativamente à interrupção da gravidez, onde o Tribunal, após declarar nula a lei, regulou a matéria de forma transitória até a entrada em vigor de novo texto criado pelo legislador.

\footnotetext{
4 Tradução nossa. No original: “(...) non si ha creazione «libera» di nuovo diritto, ma deduzione di contenuti normativi da principi presenti nell'ordinamento giuridico, e segnatamente dalla sua norma fondamentale: la manipolazione, in altri termini, avviene (e può avvenire solo se) a «rime obbligate»."

${ }^{5}$ Entre os primeiros exemplos, podemos mencionar a sentenza 190 de 1970 que declarou a omissão inconstitucional da disposição que previa a presença do Ministério Público no interrogatório do acusado. O motivo da inconstitucionalidade não residia no teor do dispositivo, mas sim, naquilo que ele não contemplava, ou seja, a necessária presença do defensor do acusado no mesmo interrogatório. Sendo assim, a Corte introduziu tal disposição ao código penal italiano com o objetivo de conformar tal regra à Constituição.
}

Revista Publicum

Rio de Janeiro, v. 3, n. 2, 2017, p. 54-77

http://www.e-publicacoes.uerj.br/index.php/publicum

DOI: 10.12957/publicum.2017.28650 
A doutrina italiana ${ }^{6}$ é pacífica no sentido de que as sentenças aditivas não têm o condão de interferir no caso de reservas absolutas do legislador, tal como ocorre no campo das infrações penais, da instituição e majoração de tributos e da fixação de remuneração de servidores públicos (NOBRE JR, 2006, p. 35-73). No mesmo sentido, encontra-se a jurisprudência da Corte Costituzionale (MALFATI; PANIZZA; ROMBOLI, 2013, p. 136). Podemos afirmar, portanto, que este seria um pré-requisito para a Corte valer-se de tal técnica, que, como visto, pode levar a uma decisão de inadmissibilidade simples ou manifesta: envio de questão que envolva escolha discricionária do legislador (ordinanza n. 198, Corte Costituzionale, 2009).

O primeiro requisito para que a Corte faça uma sentença aditiva é a impossibilidade de realizar interpretação conforme (BELLOCCI, M.; GIOVANETTI, 2010, p.15), já que o modelo italiano busca sempre "salvar a lei" da declaração de inconstitucionalidade, permitindo que o juízo a quo tente efetuar interpretação conforme antes de derradeiramente enviar o pedido de inconstitucionalidade à Corte Costituzionale (ARCIDIACONO; CARULLO; CASTORINA, 2013, p. 490). Portanto, deve ser necessária a adição de conteúdo normativo para salvar a norma da declaração de inconstitucionalidade. Conforme amplamente debatido no Direito Europeu (NETO; BORGES, 2013), para que seja possível a prolação de sentenças aditivas, dois outros requisitos devem ser observados: (i) a existência de omissão legislativa ${ }^{7}$ inconstitucional (rime obbligate, na expressão cunhada por Crisafulli (1984, p. 408), deve ser fruto de uma solução constitucionalmente obrigatória e não de um juízo discricionário); (ii) e a identificação de uma solução normativa constitucionalmente obrigatória.

Augusto Martín de La Vega (apud MENDES; BRANCO, 2012, p. 1938) ressaltou a possibilidade de utilização de decisões manipulativas de efeitos aditivos, levando-se em conta três fatores: (i) a existência de uma Carta política de perfil marcadamente programático e destinada a progressivo desenvolvimento; (ii) a permanência de um ordenamento jurídicopositivo com marcados resquícios autoritários; e (iii) a ineficácia do Legislativo para responder, em tempo adequado, às exigências de atuação da Constituição e à conformação do ordenamento preexistente ao novo regime constitucional. Assim como no modelo italiano, tais fatores se enquadram à realidade brasileira.

Verifica-se, à luz do exposto, que a norma será inconstitucional (por omissão) - enquanto não estabelece ou não prevê ou omite ou não inclui ou exclui algo que deveria incluir para ser compatível com a Constituição - ensejando, assim, o exercício subsidiário de função normativa pela Corte Constitucional, sempre nos termos da solução normativa extraída da Constituição.

${ }^{6}$ BELLOCCI, M.; GIOVANETTI, 2010, p. 16; MALFATI; PANIZZA; ROMBOLI, 2013, p. 136

7 E aqui relembrando que a omissão legislativa pode também recair sobre o Chefe do Poder Executivo ou ao Poder Judiciário quando estes tiverem a competência para iniciar o processo legislativo. Para mais informações ver capítulo 2 , (MALUF CHAVES; DOUGLAS; ARAúJO, 2014).

Revista Publicum

Rio de Janeiro, v. 3, n. 2, 2017, p. 54-77

http://www.e-publicacoes.uerj.br/index.php/publicum

DOI: 10.12957/publicum.2017.28650 
Gaetano Silvestri (1985, p. 765, apud, ANGELONE, 2006, p. 579), ao tratar das sentenças aditivas, afirma que o seu iter procedimental se divide em três partes: (i) o reconhecimento da insuficiência do texto normativo em relação à Constituição; (ii) a abstrata criação daquilo que deveria existir para que o texto possa ser constitucional; (iii) a adição do conteúdo necessário para tornar a norma constitucional.

Sistematizando, são condições para prolação de sentenças aditivas no Direito italiano: (i) ausência de matérias reservadas à discricionariedade do legislador; (ii) impossibilidade de realizar interpretação conforme; ${ }^{8}$ (iii) existência de uma omissão inconstitucional; (iv) existência de uma solução constitucionalmente obrigatória (a rimme obbligate); e (v) iter procedimental: reconhecimento da insuficiência do texto, abstrata criação e posterior adição de conteúdo.

Podemos reconhecer que as sentenças aditivas possuem peculiaridades próprias que as singularizam em relação a outras técnicas decisórias utilizadas pela Corte Constitucional, a exemplo da interpretação conforme à Constituição, conforme será demonstrado a seguir.

\section{Uma análise crítica da interpretação conforme}

Em linhas gerais, quando se fala em interpretação conforme à Constituição quer-se dizer que, no caso de existir mais de uma interpretação possível para um dispositivo legal, quando confrontado com a Constituição, deve ser dada a preferência àquela que seja conforme à Constituição (SILVA, 2006, p. 02). Logo, o parâmetro interpretativo será sempre a Constituição tomando por base uma lei infraconstitucional.

Tal técnica se origina na aplicação da interpretação conforme à Constituição (Verfassunsgskonforme Auslegung) e tem sido normalmente utilizada com a finalidade de "salvar o texto da lei" que deveria ser declarado inconstitucional (BRUST, 2009, p. 02).

A primeira referência à interpretação conforme na jurisprudência do STF pode ser verificada no voto do Min. Moreira Alves, proferido na Rep. 1417, de 1987:

A interpretação da norma sujeita a controle deve partir de uma hipótese de trabalho, a chamada presunção de constitucionalidade, da qual se extrai que, entre dois entendimentos possíveis do preceito impugnado, deve prevalecer o que seja conforme à Constituição ${ }^{9}$

Podemos retirar algumas conclusões da leitura do trecho: (i) a técnica foi adotada no país primeiramente por via jurisprudencial, ganhando previsão legal posteriormente com a Lei

8 Vale ressaltar que na jurisdição constitucional italiana, a Corte Costituzionale, através de criação jurisprudencial, abandonou a técnica de interpretação conforme (interpretazione adeguatrice) delegando esta ao juízo de primeiro grau, de modo que tal técnica tornou-se requisito de admissibilidade para análise da questão de inconstitucionalidade pela Corte.

${ }^{9}$ RTJ $126,48(53)$ 
9868/99; (ii) um dos fundamentos de validade da interpretação conforme é a presunção de constitucionalidade das leis; (iii) para que seja realizada uma interpretação conforme, é fundamental que haja mais de um entendimento possível e que no mínimo um deles seja compatível com a Constituição.

Virgílio Afonso da Silva (2006), em artigo sobre o tema, ressalta que os fundamentos principais que sustentam a possibilidade da utilização de interpretação conforme são: (i) a unidade do ordenamento jurídico e (ii) a presunção de constitucionalidade das leis.

Quanto à unidade do ordenamento, podemos realizar dois questionamentos. A doutrina normalmente costuma mencioná-lo de forma autoexplicativa para quem entende o ordenamento jurídico como uma pirâmide onde a Constituição está no ápice. Logo, a unidade do ordenamento confere validade à interpretação conforme, pois as leis infraconstitucionais devem ser interpretadas, obrigatoriamente, em consonância com a Constituição. O argumento se mostra fraco pois, como ressalta Virgílio Afonso da Silva (2006, p. 05), "ter a Constituição como parâmetro interpretativo" e "dar prioridade à interpretação que mantém a constitucionalidade da lei" são ideias diversas.

Ter a Constituição como norte interpretativo é uma característica da própria hermenêutica constitucional que é utilizada sempre no controle de constitucionalidade, de modo que não pode ser visto como um argumento que fundamenta a validade da interpretação conforme. Vale dizer, só isso não é suficiente.

Ainda sobre a unidade do ordenamento, ao se proceder a uma interpretação conforme, estar-se-ia salvando a norma da declaração de inconstitucionalidade e, assim, preservando a completude do ordenamento. Todavia, na mesma medida, declarar a inconstitucionalidade de uma lei também preserva a unidade do ordenamento, pois se expurga algo que está violando o Texto Maior.

Quanto ao segundo fundamento de validade, a presunção de constitucionalidade das leis, o autor sustenta (SILVA, 2006, p. 06) que há de fato um peso argumentativo forte, contudo incompleto. Isso seria verificado pela clara dualidade constitucionalidade/inconstitucionalidade, eis que, utilizando um sopesamento entre os argumentos que sustentam uma ou outra declaração, chegar-se-ia a decisão correta, não havendo um dever de se salvar a lei da declaração da inconstitucionalidade. Em outras palavras, ainda que existam argumentos que sustentam sua constitucionalidade, a possibilidade de declaração de inconstitucionalidade não deve ser descartada.

Após elencar tais críticas, buscamos tecer alguns comentários. A nosso sentir, os argumentos anteriores que fundamentam a validade da interpretação conforme não são inválidos, contudo, mostram-se incompletos. Vejamos.

Revista Publicum

Rio de Janeiro, v. 3, n. 2, 2017, p. 54-77

http://www.e-publicacoes.uerj.br/index.php/publicum

DOI: 10.12957/publicum.2017.28650 
Quanto à unidade do ordenamento, de fato concordamos com o autor no sentido de que ônus argumentativo precisa ser maior. Devemos considerar, além da preservação do ordenamento jurídico, as consequências da declaração de inconstitucionalidade. Ou seja, é fundamental verificar se a declaração de inconstitucionalidade cria uma lacuna perigosa que possa causar mais prejuízos do que a utilização da interpretação conforme. ${ }^{10}$

Seguindo o mesmo raciocínio, a doutrina italiana manifesta-se quando fala dos requisitos para prolação de sentenças aditivas, de modo que o raciocínio pode ser utilizado de forma analógica. A sentença aditiva é de suma importância para preservar o princípio da continuidade do ordenamento jurídico, evitando, portanto, uma lacuna perigosa no mesmo. Como salienta Modugno (1998, apud, ANGELONE, 2006, p. 566): “O vazio normativo, ut sic, com todas as suas consequências, pode comportar - e frequentemente comporta - uma situação de inconstitucionalidade mais grave em comparação àquela representada pela declaração de inconstitucionalidade." 11

Ainda vale citar a possibilidade de cominação de prazo, segundo o modelo austríaco, para que o Legislativo tenha tempo hábil para criar nova norma antes que os efeitos aditivos aconteçam (AMADEI, 2006, p. 767). Tal possibilidade coaduna-se com o necessário diálogo que deve existir entre as instituições - prestigiando, assim, a teoria dos diálogos constitucionais (BRANDÃO, 2012), sendo esse o caminho seguido pela Lei do Mandado de Injunção (Lei 13.300/16) ao adotar a corrente concretista intermediária.

Quanto à presunção juris tantum de constitucionalidade das leis, como visto inicialmente, para que seja realizada uma interpretação conforme, é necessário que haja mais de um entendimento possível e que no mínimo um deles seja compatível com a Constituição. Em havendo um entendimento que leve à inconstitucionalidade e outro que leve à constitucionalidade, é necessário que seja feito um sopesamento em relação a ambas as declarações, levando em conta, sobretudo, a prevalência dos direitos fundamentais, as cláusulas pétreas, o princípio da dignidade da pessoa humana e o respeito ao devido processo legislativo constitucional.

Por fim, vale mencionar que a utilização de tal técnica pode atenuar a tensão entre os Poderes, já que uma declaração de inconstitucionalidade constituiria uma intervenção maior do Judiciário no trabalho do Legislativo. Todavia, tal questão deve ser vista com parcimônia exatamente pelas consequências de uma interpretação conforme em questões de desacordo moral relevante ou sem critérios bem definidos.

10 Neste sentido a doutrina italiana se manifesta quando fala dos requisitos para prolação de sentenças aditivas (MODUGNO, 1998, apud, ANGELONE, 2006, p. 566).

${ }^{11}$ No original: "Il vuoto normativo, ut sic, con tutte le conseguenze, può comportare - e spesso comporta - una situazione di più grave incostituzionalità rispetto a quella rappresentata dalla legislazione incostituzionale"

Revista Publicum

Rio de Janeiro, v. 3, n. 2, 2017, p. 54-77

http://www.e-publicacoes.uerj.br/index.php/publicum

DOI: 10.12957/publicum.2017.28650 
Em suma, podemos afirmar que são condições necessárias para utilização da interpretação conforme: (i) polissemia de sentidos da norma ou impossibilidade de sentido unívoco; (ii) dentre as interpretações possíveis ao menos, uma delas deve ser compatível com a Constituição; ${ }^{12}$ (iii) a interpretação conforme deve ser mais benéfica à unidade do ordenamento do que a declaração de inconstitucionalidade; (iv) no sopesamento sobre a presunção de constitucionalidade, deve-se atentar para a prevalência de direitos fundamentais, das cláusulas pétreas, o princípio da dignidade da pessoa humana e o respeito ao devido processo legislativo em detrimento da declaração de inconstitucionalidade e também aos níveis de constitucionalidade.

\section{A utilização de sentenças aditivas pelo STF através da interpretação conforme à Constituição: um estudo da ADPF 54}

\section{(aborto de fetos anencéfalos)}

Podemos constatar que, no caso das sentenças aditivas, há, de fato, adição de conteúdo normativo ao texto, enquanto na interpretação conforme não. Ou seja, no caso das sentenças aditivas, caso a norma não sofra uma manipulação, deverá ser declarada inconstitucional: a criação é condição de sobrevivência da norma diante da omissão inconstitucional. Já na interpretação conforme, não há adição ou redução de conteúdo normativo dentre as múltiplas hipóteses de interpretação existentes: em havendo ao menos uma que seja constitucional, esta deve prevalecer desde que preserve a unidade do ordenamento e a constitucionalidade da lei seguindo os critérios já mencionados. Na interpretação conforme, o que ocorre é a escolha, dentre várias possíveis, de uma opção constitucionalmente adequada sem nenhuma manipulação do texto original ${ }^{13}$. Em suma, caso haja adição de conteúdo normativo, não estamos diante de interpretação conforme, mas sim de sentença manipulativa aditiva.

A fim de elucidar, como há confusão entre ambos os institutos, e também enaltecer sua relevância na jurisdição constitucional atual, buscaremos analisar o caso da Arguição de Descumprimento de Preceito Fundamental $54^{14}$ (aborto de fetos anencéfalos) onde pode-se verificar a íntima relação entre as sentenças aditivas e a interpretação conforme à Constituição.

12 Caso exista mais de uma interpretação conforme à Constituição, a Corte pode escolher aquela que achar mais constitucionalmente adequada ou realizar consoante a Corte Costtizuionale italiana, uma sentença aditiva de princípio que cria um princípio que irá nortear o Legislador na futura criação de norma e os juízes de primeiro grau. Cria-se, assim, verdadeiro diálogo entre as instituições e dentro do Poder Judiciário.

${ }^{13}$ Brust (2009, p.12) afirma que a interpretação conforme à um antecedente da sentença aditiva, já que primeiro se verifica a possibilidade de interpretação conforme para depois analisar quanto há necessidade de adição de conteúdo.

${ }^{14}$ STF, ADPF 54, Rel. Min. Marco Aurélio, j. 12/04/2012, Dje. 20/04/2012

Revista Publicum

Rio de Janeiro, v. 3, n. 2, 2017, p. 54-77

http://www.e-publicacoes.uerj.br/index.php/publicum

DOI: 10.12957/publicum.2017.28650 
Analisando o voto do Min. Gilmar Mendes, verificamos que, sob o manto da interpretação conforme à Constituição e da declaração de inconstitucionalidade parcial sem redução de texto, o STF já vem realizando sentenças aditivas, ainda que sem utilizar tal denominação:

Em outros vários casos mais antigos [ADI 3324, ADI 3046, ADI 2652, ADI 1946, ADI 2209, ADI 2596, ADI 2332, ADI 2084, ADI 1797, ADI 2087, ADI 1668, ADI 1344, ADI 2405, ADI 1105, ADI 11275], também é possível verificar que o Tribunal, a pretexto de dar interpretação conforme a Constituição a determinados dispositivos, acabou proferindo o que a doutrina constitucional, amparada na prática da Corte Constitucional italiana, tem denominado de decisões manipulativas de efeitos aditivos [26]. São vários os exemplos, a partir do caso do direito de greve do servidor público, mandado de injunção, ou mesmo o caso da relatoria de Vossa Excelência, Ministro Britto, a propósito do tema Raposa Serra do Sol, em que o Tribunal consagrou todos aqueles itens procedimentais a propósito dessa controvérsia.

O caso guarda pertinência ímpar em razão do voto do Min. Gilmar Mendes, onde discorre sobre o instituto das sentenças aditivas, bem como reafirma a crítica já exposta no sentido de que o STF ainda se abstém de reconhecer seu papel criativo.

A ADPF $54^{15}$ foi proposta pela Confederação Nacional dos Trabalhadores na Saúde (CNTS) com a finalidade de permitir a interrupção de gravidez em casos de gestação de feto com anencefalia, conferindo interpretação conforme à Constituição e a consequente inimputabilidade da gestante e dos profissionais da saúde pelos crimes previstos nos artigos 124, 126 e 128, I e II, do Código Penal.

A pretensão da arguente foi assim exposta:

Que essa Eg. Corte, procedendo à interpretação conforme à Constituição dos arts. 124, 126 e 128, I e II, do Código Penal (Decreto-Lei no 2.848/40), declare inconstitucional a interpretação de tais dispositivos como impeditivos da antecipação terapêutica do parto em casos de gravidez de feto anencefálico, diagnosticados por médico habilitado, reconhecendo-se o direito subjetivo da gestante a se submeter a tal procedimento sem a necessidade de apresentação prévia de autorização judicial ou qualquer outra forma de permissão específica do Estado.

A ementa do acórdão ficou da seguinte forma:

FETO ANENCÉFALO - INTERRUPÇÃO DA GRAVIDEZ - MULHER - LIBERDADE SEXUAL E REPRODUTIVA - SAÚDE - DIGNIDADE - AUTODETERMINAÇÃO DIREITOS FUNDAMENTAIS - CRIME - INEXISTÊNCIA. Mostra-se inconstitucional interpretação de a interrupção da gravidez de feto 
anencéfalo ser conduta tipificada nos artigos 124, 126 e 128, incisos I e II, do Código Penal.

Não há um conceito expresso pelo Supremo Tribunal Federal no tocante à interpretação conforme, tampouco à declaração de inconstitucionalidade parcial sem redução de texto. Entende-se, neste estudo, que a declaração de inconstitucionalidade parcial sem redução de texto seria aquela técnica de decisão cujos efeitos ensejam uma declaração de inconstitucionalidade de determinada interpretação que seja incompatível com a Constituição.

Em suma, na interpretação conforme, a Corte afirma o caminho a ser seguido para que haja compatibilidade com a Constituição, enquanto na declaração de inconstitucionalidade parcial sem redução de texto o Tribunal, diz qual é a interpretação que deve ser rechaçada.

Como visto, a arguente pleiteava a interpretação conforme para que a Corte declarasse a inconstitucionalidade da interpretação de dispositivos do Código Penal "como impeditivos da antecipação terapêutica do parto em casos de gravidez de feto anencefálico". Ressalte-se que não se fala em aborto, tampouco na ementa o termo é mencionado. Em outras palavras, através da interpretação conforme, buscou-se declarar inconstitucional determinada interpretação o que veio a gerar, segundo a ementa, uma atipicidade das condutas perpetradas pela mulher e pelo médico.

Em realidade, a nosso sentir, o Supremo Tribunal Federal, através de uma interpretação conforme, com efeitos de declaração de inconstitucionalidade parcial sem redução de texto - já que declarou tal interpretação contrária à Constituição, criou em verdade, uma sentença aditiva in bonam partem incluindo, na prática, uma excludente de ilicitude ao crime de aborto, muito embora o termo não seja mencionado.

Neste sentido, manifestou-se o Ministro César Peluso em seu voto: “No fundo se trata-e nisso não há dúvida alguma - de criar, à margem da interpretação das normas de caráter penal, mais uma excludente de ilicitude.". No mesmo sentido, votou o Ministro Carlos Velloso: "Pretende-se, mediante interpretação da lei penal conforme a Constituição, instituir uma terceira excludente de criminalidade relativamente ao crime de aborto. O que se pretende, portanto, é que o Supremo Tribunal Federal inove no mundo jurídico. E inove mediante interpretação".

A Ministra Ellen Gracie, em seu voto, refere-se à prolação de sentença aditiva:

o objeto da ação é o de acrescentar conteúdos à norma vigente. Ora, a jurisdição constitucional é normalmente convocada para expungir do ordenamento normas que estejam em descompasso com a Constituição, não para oferecer acréscimos ao ordenamento positivo em usurpação à competência dos outros dois poderes. Circunstâncias há, porém, em que as disposições de inconstitucionalidade tornam necessário o preenchimento de lacunas criadas pela própria decisão, por isso, fala-se em efeitos aditivos que podem ter as sentenças dos Tribunais Constitucionais.

Revista Publicum

Rio de Janeiro, v. 3, n. 2, 2017, p. 54-77

http://www.e-publicacoes.uerj.br/index.php/publicum

DOI: $10.12957 /$ publicum.2017.28650 
Restou caracterizada, segundo aqui se defende, uma sentença aditiva com a criação de uma excludente de ilicitude, sendo reconhecida, inclusive, pelos votos dissidentes: Ellen Gracie, Carlos Velloso, Eros Grau e César Peluso (PAIVA, 2008/2009, p. 10).

O Min. Ayres Britto ressalta, em seu voto, que "pelo menos três acepções ou representações mentais ou conteúdos semânticos podem ser extraídos dos signos linguísticos em que se vaza o discurso legal". A primeira delas é de que a antecipação terapêutica do feto anencéfalo é crime. A segunda delas é que não há crime de aborto no caso de interrupção voluntária de gestação que tenha por objeto um "natimorto cerebral". A terceira seria a interpretação de que a antecipação da gravidez de feto anencéfalo é crime, fato típico, contudo não configura prática punível. Contudo, ele não menciona a utilização de sentenças aditivas e sustenta que todas as possibilidades tratam de interpretação conforme.

O Ministro Gilmar Mendes, em seu voto, além de reconhecer o uso de tal técnica e dos seus efeitos, fomenta sua utilização, diferentemente de seus pares, criando, inclusive, condições para que o aborto de fetos anencéfalos seja realizado ${ }^{16}$. Ademais, ressalta que as sentenças aditivas surgem como uma ferramenta importante no combate à omissão inconstitucional ratificando a superação do ultrapassado paradigma kelseniano:

Assim, observe-se que, nesta ADPF 54, Rel. Min. Marco Aurélio, em que se discute a constitucionalidade da criminalização dos abortos de fetos anencéfalos, caso o Tribunal decida pela procedência da ação, dando interpretação conforme aos arts. 124 a 128 do Código Penal, invariavelmente proferirá uma típica decisão manipulativa com eficácia aditiva.

Ao rejeitar a questão de ordem levantada pelo Procurador-Geral da República, o Tribunal admitiu a possibilidade de, ao julgar o mérito da ADPF 54, atuar como verdadeiro legislador positivo, acrescentando mais uma excludente de ilicitude - no caso de o feto padecer de anencefalia - ao crime de aborto. Isso quer dizer que, pelo menos segundo o meu voto, está rechaçado o argumento da autora, de atipicidade do fato. Acolho a hipótese de que a Corte criará, ao lado das já existentes (art. 128, I e II), uma nova hipótese de excludente de ilicitude do aborto. Portanto, não se pode negar que o Supremo Tribunal Federal está a se livrar do vetusto dogma do legislador negativo e, nesse passo, alia-se à mais progressiva linha jurisprudencial das decisões interpretativas com eficácia aditiva, já adotadas pelas principais Cortes Constitucionais europeias. A assunção de uma atuação criativa pelo Tribunal poderá ser determinante para a solução de antigos problemas relacionados à inconstitucionalidade por omissão, que

\footnotetext{
16 “Conclusão: (...) Para o cumprimento desta decisão, é indispensável que o Ministério da Saúde regulamente adequadamente, com normas de organização e procedimento, o reconhecimento da anencefalia. Enquanto pendente regulamentação, a anencefalia deverá ser atestada por no mínimo dois laudos diagnósticos, produzidos por médicos distintos, e segundo técnicas de exame atuais e suficientemente seguras. Para o cumprimento desta decisão, é indispensável que o Ministério da Saúde regulamente adequadamente, com normas de organização e procedimento, o reconhecimento da anencefalia. Enquanto pendente regulamentação, a anencefalia deverá ser atestada por no mínimo dois laudos diagnósticos, produzidos por médicos distintos, e segundo técnicas de exame atuais e suficientemente seguras."
} 
muitas vezes causa entraves para a efetivação de direitos e garantias fundamentais assegurados pelo texto constitucional.

Consoante exposto anteriormente, a Corte Costituzionale e a doutrina italiana têm entendimento sedimentado no sentido de que não se mostra legítima a utilização de sentenças aditivas em matérias reservadas à discricionariedade do legislador, como, por exemplo, em matéria penal. Todavia, admite-se sua prolação em hipótese de criação in bonam partem (MALUF, 2016, p. 07/08), ficando sempre reservada ao legislador a possibilidade da criação normativa devida. Neste sentido, afirma o Min. Gilmar Mendes em seu voto:

É certo que a incidência de decisões com efeitos aditivos em matéria criminal não está livre de críticas. Parece sensato assumir todas as cautelas quando se trata de produzir decisões manipulativas sobre normas de caráter penal, tendo em vista os princípios da legalidade (e reserva de lei e reserva de Parlamento) e da tipicidade (cerrada) penal. A sentença aditiva in malam partem é extremamente reprovável, todavia, se proferida in bonam partem, abre-se uma brecha explorável para a prolação de decisão manipulativa que tenha efeito restritivo da norma penal, não ofensiva ao postulado da reserva de lei. Faço, no entanto, uma imprescindível ressalva: é que as decisões manipulativas de efeitos aditivos, como essa que se propõe, devem observar limites funcionais claros, isto é, elas devem submeter-se à liberdade de conformação do legislador, que poderá, a qualquer tempo, editar norma sobre o tema. Desse modo, é preciso reconhecer que a decisão desta Corte não impedirá o advento de legislação sobre o assunto, devendo antes servir de estímulo à atuação do legislador.

A questão tem precedente semelhante na jurisprudência da Corte italiana (MALUF, 2016, p.

07/08). Dentre as decisões aditivas “tradicionais”, cumpre citar a sentença 27/1975.

No caso da sentença 27 de 1975 - criação de uma hipótese de aborto -, foi declarada a inconstitucionalidade por omissão parcial (dichiarazione di parziale illegittimità costituzionale) do art. 546 do Código Penal na parte em que não previa que a gravidez pode ser interrompida quando a gestação ulterior implicar dano, perigo, gravidade, comprovada por médico, cujo fundamento seja inevitável, para a saúde da mãe. Entendeu-se que o dispositivo violara os arts. 31 e 32 da Constituição Italiana, que preveem a proteção da maternidade, a saúde como direito fundamental e a impossibilidade de a lei violar os limites impostos pelo respeito à pessoa humana.

Na sentença 354 de 2002, foi declarada a inconstitucionalidade do art. 688, 2, do Código Penal, na parte em que pune com pena de prisão de 3 a 6 meses qualquer um que, em lugar público, é pego em estado de manifesta embriaguez, se o fato é cometido por agente que já possui uma condenação por crime doloso contra a vida ou integridade física individual. Os argumentos lastrearam-se na violação de dispositivos constitucionais: art. $3 \underline{0}$ - direito à 
dignidade e igualdade -, art. 25, 2 - princípio da legalidade - e art. 27, 3 - a pena não pode conter tratamento desumano ou deve servir a reeducação do condenado.

A sentença enfatizou a questão da desproporcionalidade com a criação de uma hipótese que violava o princípio da igualdade, já que direcionava a norma penal, de forma irrazoável, para uma categoria específica de sujeitos: os alcoólatras. Segundo a ratio decidendi, isso violaria também os princípios da lesividade, legalidade e materialidade da lei penal, nos termos do art. 27, 3, da Constituição Italiana.

Na sentença 101 de 1999, a Corte declarou a inconstitucionalidade por omissão do art. 376, 1, do Código Penal, na parte em que não previa a retratação como causa de não punibilidade, para aquele que a pedido da polícia ou sob delegação do Ministério Público para fornecer informações sobre a investigação, tenha prestado declarações falsas no todo ou em parte, mas depois se retratava.

Também nesse caso, a sentença aditiva foi prolatada pela violação do princípio da igualdade, art. 3o da Constituição Italiana, eis que o Código Penal previa outras hipóteses de retratação inclusive aquela do caso em comento, mas somente quando feita ao Ministério Público e não à polícia. Ressaltou a Corte, na fundamentação, que "o princípio da igualdade é uma exigência na margem de conformidade do legislador", ou seja, deve funcionar como norte da atuação legiferante.

Da análise feita, podemos inferir que o caso julgado pelo STF é compatível com o modelo italiano, de modo que a Corte, a nosso sentir, acertou quanto ao mérito, mas falhou quanto à técnica de decisão escolhida, ao abster-se de ratificar seu papel criativo, mantendo a afirmação de que utiliza interpretação conforme e não sentença aditiva. Ainda assim, os debates realizados em torno da possibilidade ou não de prolação de sentenças aditivas e o voto do Ministro Gilmar Mendes contribuíram para o desenvolvimento e aprofundamento do tema na jurisprudência da Corte.

\section{Críticas à utilização de sentenças aditivas pelo STF e a necessidade de evolução do paradigma kelseniano}

As principais críticas à atuação do STF como prolator de sentenças aditivas são as seguintes: i) a Corte Constituzionale, ao contrário do STF, é um Tribunal ad hoc, ou seja, que não faz parte do Poder Judiciário e, portanto, diferentemente do Supremo Tribunal Federal, estaria equidistante para julgar; ii) o STF deve agir somente como legislador negativo, conforme a tradição kelseniana; iii) tal técnica de decisão viola a separação dos Poderes, pois o STF atua como legislador positivo 
substituindo o Congresso; (iv) a Corte não detém legitimidade constitucional para prolatá-las, eis que seus membros não são escolhidos pelo povo.

Tais argumentos, contudo, não são unânimes se analisada a compreensão contemporânea da jurisdição constitucional brasileira e de suas condições jurídicas e institucionais. Lenio Streck (2013, p. 451), ao tratar da criação de Tribunais ad hoc e o controle de constitucionalidade feito pelos Tribunais Europeus, afirma que tal configuração decorre do antigo temor em relação aos juízes no período da Revolução Francesa. Contudo, em que pese o embasamento histórico, o modelo kelseniano de Tribunal ad hoc não foi adotado pelos Tribunais Europeus, ao menos não completamente. Isso se comprova porque o formato estrutural-normativista de Kelsen, que via a atuação do Tribunal Constitucional ad hoc como mero legislador negativo, não previu - e nem poderia - o desenvolvimento de Constituições de caráter dirigente e programático, com força normativa para serem executadas, jurisdições constitucionais amplas e conceitos indeterminados (STRECK, 2013, p. 455).

A retirada do controle de constitucionalidade de um órgão integrante do Poder Judiciário (ad hoc) diminui, em tese, as tensões que permeiam o processo constitucional. Todavia, é impossível eliminá-las por completo. Prova disso é que a própria Corte Costituzionale italiana adota uma postura de autocontenção diante de questões que demandam valoração de natureza política ou uso da discricionariedade do legislador. A expansão (redimensionamento) das funções dos Tribunais Constitucionais surge como resposta às crises das instituições democráticas. Em razão do conteúdo das Constituições contemporâneas, é da natureza das Cortes participar da função legiferante (STRECK, 2013, p. 772). Valendo ressaltar que o Judiciário nunca possuirá a mesma liberdade de conformação do legislador, já que a moldura criativa do intérprete é restringida pela própria Constituição e pela provocação, ao contrário do Legislativo que age de ofício; e, em todo o caso, a sentença aditiva somente será cabível na hipótese de obrigatoriedade para o legislador que se mantém inerte (ABBOUD, 2009, p. 187).

Como já mencionado, atribui-se a Kelsen (1998, p. 153) a afirmação de que o intérprete da Constituição, no exercício do controle de constitucionalidade, não poderia ir além da invalidação da norma. Daí surge o postulado de que a Corte Constitucional deve atuar como legislador negativo e nunca o contrário.

Carlos Alexandre de Azevedo Campos (2011, p. 79), ao abordar as sentenças aditivas e a realidade brasileira, ressalta com maestria que o Constituinte não destinou ao STF um papel de mero expectador na balança entre os Poderes diante do caráter analítico/programático da Constituição e da omissão inconstitucional:

Revista Publicum

Rio de Janeiro, v. 3, n. 2, 2017, p. 54-77

http://www.e-publicacoes.uerj.br/index.php/publicum

DOI: 10.12957/publicum.2017.28650 
Sem embargo, no Brasil, a relação entre o sistema de controle de constitucionalidade e a ordem constitucional como um todo revela tanto que caducou a ideia kelseniana do juiz constitucional como legislador negativo quanto transparece a necessidade de uma coordenação mais dinâmica e cooperativa entre os poderes constituídos para a realização desta mesma ordem constitucional. O papel fundamental atribuído à lei para a dinâmica de concretização da Constituição de 1988 aponta para a prioridade do Legislativo na tarefa de construir e complementar os significados constitucionais. O amplo catálogo de competências atribuídas ao Poder Executivo, nos três níveis da Federação, revela o papel fundamental que a Constituição Ihe reservou na execução de políticas públicas, regulação e fiscalização de atividades econômicas, prestação de diversos serviços públicos, entre outras atividades. Por sua vez, o catálogo constitucional de princípios e direitos fundamentais (arts. 1ำ, 5ㅇ, 6으, 7으, 8으, 9으, etc.), a previsão constitucional de aplicabilidade imediata destes direitos (art. 5ㅇ, § 1ㅇ), a atribuição expressa do papel de guardião da Constituição ao Supremo Tribunal Federal (art. 102, caput) e a disciplina constitucional de um amplo arsenal de instrumentos processuais para a garantia judicial da normatividade da Constituição pela mesma Corte (arts. 102, 103 e 103-A) deixam claro que a vontade do constituinte é de um comportamento institucional do Supremo que em nada combina com a passividade do juiz constitucional kelseniano e nem com um padrão rígido e ortodoxo de separação de Poderes, mas, ao contrário, o constituinte de 1988 e o das reformas construíam um Tribunal Constitucional que deve controlar efetivamente a legitimidade constitucional dos atos dos demais poderes constituídos e que deve superar afirmativamente os vazios legislativos inconstitucionais.

Georges Abboud (2009, p. 128), com base em Friedich Müller, afirma que Kelsen estava muito mais preocupado com a coerência lógica dos enunciados da ciência do direito do que com a atividade interpretativa, de modo que seria incoerente usar a doutrina kelseniana para obstar a utilização de decisões modificativas pelo Supremo: as sentenças da Corte têm caráter jurisdicional e não legislativo negativo. Não seria correto, portanto, entender que um Tribunal Constitucional atua como legislador negativo.

Rodrigo Brandão (2014, p. 03) aduz que, de fato, o normativismo kelseniano atribui o papel de legislador negativo ao Tribunal Constitucional, contudo Kelsen reconhecia expressamente a dimensão criativa da atuação da Corte no caso de conceitos abertos (2014, p. 05), de modo que, para evitar que isso ocorresse, a Constituição deveria possuir regras precisas com parâmetros de controle. Em outras palavras, o papel da Corte em havendo conceitos abertos e normas principiológicas vai além de mero legislador negativo aplicador da Constituição. Neste sentido:

Tais considerações são suficientes para se compreender que o argumento de que o STF, por atuar como mero "legislador negativo", limitar-se-ia a aplicar a Constituição, não atuando criativamente em qualquer medida, não encontra fundamento em Kelsen (BRANDÃO, 2014, p. 04). 
Reconhece-se, assim como Kelsen, a dimensão criativa da atividade judicial, pois considera o texto normativo como resultado da interpretação já que o intérprete inexoravelmente realiza um processo de (re)construção de significados tendo no texto seu limite (BRANDÃO, 2014, p. 27). Assim, a grande questão não é a existência ou não de criação judicial, eis que inerente ao processo interpretativo, mas sim os limites na judicial review (BRANDÃO, 2014, p. 28).

Acerca do tema, Lenio Streck (2013, p. 761) sustenta que, na medida em que um texto é válido se estiver em conformidade com a Constituição, os textos infraconstitucionais necessariamente precisam passar pelo chamado "banho de imersão constitucional", o que acarreta inexoravelmente tensões na relação entre os poderes. Isso, segundo o autor, deve ser assumido como um componente da própria formulação do Estado Democrático de Direito (2013, p. 761), de modo que a morte da tradicional tese da separação dos poderes implica, a toda evidência, o abandono da tese como juiz "exegeta boca da lei" e dos tribunais constitucionais como legisladores negativos.

Ainda Streck (2013, p. 746/772) afirma que não há mais como conceber o ultrapassado paradigma de legislador negativo proposto por Kelsen, seja no Brasil, seja em países europeus que adotaram o sistema de Tribunal ad hoc, pelos seguintes fundamentos: i) o alargamento (redimensionamento) das funções dos Tribunais Constitucionais surge como resposta às crises das instituições democráticas; ii) a morte dos juízes como meros " exegetas bocas da lei" implica necessariamente na extinção do dogma de legislador negativo, por razões de desenvolvimento jurídico e democrático; iii) a instituição da interpretação conforme pela Lei 9.868/99 foi uma confirmação do próprio Legislativo no sentido de que o Judiciário pode, expressamente, atuar através de adaptação e adição/adjudicação do sentido dos textos normativos, reconhecendo, assim, a expansão da sua atuação para além de mero legislador negativo.

Ademais, conforme o sistema de escalonamento normativo proposto por Kelsen, onde a Constituição encontra-se no ápice, depreende-se que, exatamente em razão da posição de supremacia que a Constituição exerce no ordenamento, mostra-se possível a utilização de sentenças aditivas com vistas a gerar a eficácia da norma fundamental e a compatibilidade das leis à sua posição privilegiada, mais ainda quando estamos diante de uma Carta altamente compromissória, analítica e dirigente.

Não é razoável aplicar a ideia de um juiz kelseniano a uma Constituição não kelseniana com inúmeros conceitos indeterminados e caráter principiológico, sobretudo quando o próprio autor reconhecia essa possibilidade.

O Estado através de suas instituições deve agir em prol do povo que o legitima, a inércia ou omissão de um Poder para efetivar direitos pode e deve ser suprida pelo Judiciário. Tal

Revista Publicum

Rio de Janeiro, v. 3, n. 2, 2017, p. 54-77

http://www.e-publicacoes.uerj.br/index.php/publicum

DOI: 10.12957/publicum.2017.28650 
raciocínio decorre da própria teoria constitucional, eis que os ministros, embora não sejam diretamente escolhidos, compõem a Corte que guarda a Constituição, sendo escolhidos pelo Executivo e sabatinados pelo Senado, ou seja, passando pelo crivo daqueles que foram eleitos pelo povo. Assim como na Itália, onde os membros da Corte Costituzionale não são eleitos, sua legitimidade decorre da Constituição e do próprio princípio democrático. Neste sentido, aduz Alexandre de Moraes (2014):

A justiça constitucional, porém, não carece de legitimidade, pois a Constituição Federal consagrou a ideia de complementaridade entre democracia e Estado de Direito, pois enquanto a democracia se consubstancia no governo da maioria, baseado na soberania popular, o estado de direito consagra a supremacia das normas constitucionais, o respeito aos direitos fundamentais e o controle jurisdicional do poder estatal, não só para proteção da maioria, mas também, e basicamente, dos direitos da minoria; sendo absolutamente necessária a compatibilização do parlamento (que representa o princípio democrático da maioria) com ajustiça constitucional (que representa a garantia do estado de direito e a defesa dos direitos fundamentais e dos direitos da minoria).

No mesmo sentido, sustenta Luís Roberto Barroso ${ }^{17}$ afirmando que, muitas vezes, o ônus político de algumas decisões ou a falta de consenso no Legislativo inviabilizam a concretização de Direitos o que justificaria uma atuação do Tribunal Constitucional. Tal conduta, longe de ser configurada como ativismo judicial, mostra-se em consonância com o papel representativo que a Corte desempenha, eis que age em respeito ao princípio democrático, pois todo Poder Político, independentemente de ser eleito, age em nome do povo:

Quando o Legislativo não tenha atuado em uma matéria em que a Constituição tenha determinado sua atuação ou quando estivessem em jogo direitos fundamentais, ai diante da eventual inercia do legislador, ou da omissão do Executivo, o Judiciário não só pode como deve atuar porque ele tem o dever de fazer valer a Constituição e o dever de tomar decisões envolvendo os casos concretos.(...) Nesses casos de omissão em que o Judiciário acaba criando a norma ele funciona como o representante argumentativo da sociedade, para usar uma expressão consagrada pelo professor alemão Robert Alexy. A democracia é feita de votos e esta é uma dimensão importante. Mas ela não é feita só de votos. A democracia é feita de votos, de direitos e de razões. Portanto, é a capacidade do Judiciário oferecer razões às suas decisões criativas que fazem com que as suas decisões tenham uma legitimação, na capacidade de justificar, que aquela é a solução justa e constitucionalmente adequada." 18

A própria Constituição de 1988 dispôs sobre a possibilidade de prolação de sentenças aditivas quando previu o Mandado de Injunção, sendo que, conforme já exposto, a Lei que o

\footnotetext{
${ }^{17}$ Palestra no canal da UNICEUB em março de 2015, disponível em <https://www.uniceub.br/eventos-academicos/eventospor-curso/1o-semestre-2015/palestra-online-do-ministro-luis-roberto-barroso.aspx> Acesso em 24 de março de 2015
} 18 Idem.

Revista Publicum

Rio de Janeiro, v. 3, n. 2, 2017, p. 54-77

http://www.e-publicacoes.uerj.br/index.php/publicum

DOI: 10.12957/publicum.2017.28650 
regulamentou previu expressamente a adoção da corrente concretista intermediária em seu bojo, possibilitando, assim, a utilização de sentenças aditivas pelo Judiciário. Conforme visto em ponto anterior, Lenio Streck (2013, p. 753) também sustenta sua possibilidade em virtude da previsão expressa da técnica de interpretação conforme, afirmando que não se trata de violação da separação dos Poderes:

\begin{abstract}
À evidência, isso não significa que o Judiciário se transformará em legislador positivo. $O$ instituto da interpretação conforme não tem o condão de transformar o Judiciário em um Poder que está acima da Constituição. (...) Quando se adiciona sentido ou se reduz sentido (ou a própria incidência de uma norma) estar-se-á fazendo algo que vai além ou aquém do texto da lei, o que não significa afirmar que o Tribunal está legislando. Pelo contrário. Ao adaptar o texto legal à Constituição, a partir dos diversos mecanismos hermenêuticos existentes, o juiz ou tribunal estará tão somente cumprindo sua função de guardião de constitucionalidade das leis. (2013, p. 753)
\end{abstract}

Por fim, se considerarmos que a Constituição resguarda direitos fundamentais e cabe ao Judiciário a sua guarda, cabe também a ele o dever de concretizá-los, sobretudo quando há inércia do Executivo e do Legislativo ${ }^{19}$

Vale ressaltar que a atuação criativa da Corte parece causar transtornos ao Legislativo (e eventuais reversões legislativas) apenas em matérias que geram alguma espécie de repercussão social, política e eleitoral, visto que em diversos casos - não regulamentação do direito de greve dos servidores públicos, não regulamentação da lei criação de novos municípios e não elaboração de lei de revisão geral anual - o apelo do Supremo ao legislador foi inócuo, o que acaba fomentando a atuação do Tribunal (FILHO, 2016a, p. 101/102).

Assim, é preciso que o STF avance reconhecendo que pode prolatar sentenças aditivas (o que, ao fim e ao cabo, já ocorre através da interpretação conforme). Essa postura é fundamental para que haja o devido controle do Judiciário através da necessária accountability (MALUF, 2016a).

Reconhecer a possibilidade jurídica e a singularidade dessa importante técnica de decisão é o primeiro passo para o desenvolvimento de parâmetros bem delimitados: o estabelecimento de standards, seja através da doutrina ${ }^{20}$, seja da jurisprudência da Corte, revela-se imprescindível para garantir segurança jurídica - evitando abusos e conflitos institucionais - e a verdadeira efetividade da Constituição.

${ }^{19}$ SOUZA NETO, Cláudio Pereira de. Teoria da constituição, democracia e igualdade, p. 26

20 Neste sentido, em relação ao mandado de injunção, Ademar Borges (2016, p. 263) afirma que havendo ausência de norma regulamentadora de direito materialmente fundamental a prolação de sentença aditiva na concessão da injunção mostra-se altamente recomendável no campo da proteção de direitos das minorias e pouco recomendável no caso de regulamentação e disciplina de direitos econômicos e sociais. Também afirma que a atuação criativa deve ser suficiente e necessária para superar a omissão inconstitucional com a menor intromissão possível (2016a, p. 105/106). 
Conforme ressalta Georges Abboud (2009, p. 184), as decisões manipulativas constituem uma realidade do desenvolvimento da jurisdição constitucional, de modo que muito mais importante do que se discutir a possibilidade ou não da existência dessas modalidades de decisão, é importante precisar seus limites e efeitos.

Há, portanto, abordagens distintas em relação ao papel da jurisdição constitucional, os limites da atuação de um Tribunal Constitucional e a abordagem correta na tensão causada pela omissão do legislador em relação aos mandamentos constitucionais. Independente da posição adotada - a clássica concepção do legislador negativo ou a de um juiz atuante e responsável por suprir as lacunas do sistema -, é fundamental reconhecer que, na atualidade, o Supremo Tribunal Federal do Brasil tem tomado decisões aditivas sem que assim o reconheça. Reconhecer o uso do instrumento é o primeiro passo necessário para se traçar os parâmetros de atuação de si próprio.

\section{Conclusão}

A partir da análise feita, podemos afirmar que os desafios futuros para a hermenêutica constitucional são grandes. O ordenamento jurídico brasileiro, assim como ocorre na Itália, é vítima da omissão histórica do legislador, de modo que uma atuação criativa da Corte é uma consequência da evolução do Direito em prol da sua unidade e da eficácia constitucional. Somado a isso, a judicialização da política, a ampla jurisdição constitucional no Brasil e os conceitos ambíguos e indeterminados da Constituição analítica geram um campo fértil para o desenvolvimento de técnicas interpretativas.

A interpretação conforme à Constituição é um instrumento legítimo e eficaz no combate a celeumas envolvendo normas inconstitucionais que, caso sejam expurgadas do ordenamento, levem a um vazio perigoso e também no caso de divergências hermenêuticas. Contudo, tal técnica não se mostra suficiente para resolver os problemas que se apresentam. É preciso evoluir. O necessário reconhecimento de que a sentença aditiva é um instrumento utilizado pela Corte brasileira essencial para um aperfeiçoamento da hermenêutica e da jurisdição constitucional, inclusive para estabelecer limites à sua atuação criativa.

O Supremo Tribunal Federal não reconhece a possibilidade de utilização aditiva de forma clara, muito embora já se utilize de tal técnica decisória sob a nomenclatura de interpretação conforme ou inconstitucionalidade parcial sem redução de texto.

$\mathrm{Na}$ quadra atual em que o papel da Corte Suprema se encontra potencializado, torna-se extremamente relevante a criação de uma Teoria da Decisão Judicial com o objetivo de evitar que a Constituição perca sua eficácia diante dos conflitos institucionais que podem ser causados por uma atuação decisicionista sem critérios bem definidos. 
A grande questão não deve mais ser a existência ou não de criação judicial de Direito — eis que inerente ao processo interpretativo -, mas sim os limites dessa criação. 0 reconhecimento da possibilidade de prolação de sentenças aditivas contribui, não só para um amadurecimento da jurisdição constitucional - como instrumento dialógico de aprimoramento institucional entre Legislativo e Judiciário - , mas, sobretudo, torna-se essencial para um controle da atuação do órgão jurisdicional (no sentido de accountability).

É imprescindível que a Corte evolua seu entendimento e assuma de forma nítida e transparente esse papel criativo em prol do aprimoramento da jurisdição constitucional e da plena efetividade da Constituição.

\section{Referências}

ABBOUD, Georges. Sentenças interpretativas, coisa julgada e súmula vinculante: alcance e limites dos efeitos vinculante e erga omnes na jurisdição constitucional. Dissertação - Mestrado em DIREITO Instituição de Ensino: PONTIFÍCIA UNIVERSIDADE CATÓLICA DE SÃO PAULO, SÃO PAULO Biblioteca Depositária: PUC-SP, 309 fl. 2009.

AMADEI, Leonetto. Intervento su Parlamento e Corte Costituzionale. Collana "1956-2006, Cinquant'anni di Corte Costituzionale" (Obra Coletiva), Tomo II, Ed, Corte Costituzionale, 2006;

ANGELONE, Marco. Sentenze additive della Corte costituzionale e interpretazione adeguatrice. In: Interpretazione a fini applicativi e legittimità costituzionale. Collana "Cinquanta anni della Corte Costituzionale della Reppublica italiana", Femia Pasquale. Edizioni Scientifiche Italiane, 2006;

ARCIDIACONO, L.; CARULlO, A.; CASTORINA, E. Diritto Costituzionale. 2a Ed. CEDAM, 2013.

BARROSO, Luis Roberto. O Controle de Constitucionalidade no Direito Brasileiro - 6a Ed. - Rio de Janeiro: Saraiva,

2012;

BELLOCCI, M.; GIOVANETTI, T. Il quadro delle tipologie decisorie nelle pronunce della Corte Costituzional. QUADERNO PREDISPOSTO IN OCCASIONE DELL'INCONTRO DI STUDIO CON LA CORTE COSTITUZIONALE DI UNGHERIA. 2010. Disponível em: < http://www.cortecostituzionale.it/documenti/convegni seminari/STU\%20219 Tipologia decisio ni.pdf > Acesso em: 13 de out de 2014.

BRUST, Leo. A interpretação conforme a constituição e as sentenças manipulativas. Rev. direito GV [online]. 2009, vol.5, n.2, pp. 507-526. Disponível em: < http://direitogv.fgv.br/sites/default/files/14 2.pdf > Acesso em: 20 novembro 2013;

BOSELLI, Luis Henrique. As sentenças aditivas na jurisdição constitucional. Revista Jurídica ESMP $-\mathrm{SP}, \mathrm{V} .3,2013$.

BRANDÃO, Rodrigo. Supremacia Judicial versus Diálogos Constitucionais. A quem cabe a última palavra sobre o sentido da Constituição? Rio de Janeiro: Lúmen Juris, 2012. 
STF e o dogma do legislador negativo. Revista Direito Estado e Sociedade. N 44. p. 189 a 220. Jan-jul 2014.

CAMPOS, Carlos de Alexandre de Azevedo. Atualidades do Controle Judicial da Omissão Legislativa. DPU № 42 - $\quad$ Nov-Dez/2011. Disponível em: < http://www.direitopublico.idp.edu.br/index.php/direitopublico/article/viewFile/1124/1138 $>$ Acesso em: 23 de junho de 2014.

CRISAFULLI, Vezio. Lezioni di Diritto Costituzionale, II, Padova, 1984.

DOUGLAS, William.; ARAÚJO, Eugênio Rosa de.; CHAVES, André Luiz Maluf.;. Omissão Inconstitucional e Revisão Geral Anual dos Servidores Públicos. 1 a ed, Impetus, Niterói, 2014.

FILHO, Ademar Borges de Sousa. Sentenças aditivas na jurisdição constitucional brasileira. Fórum, 2016.

Pontes de transição entre direito e política: sentenças aditivas na experiência recente do STF. Revista Publicum Rio de Janeiro, Número 2, 2016, p. 74-111.

ISRAEL, Lucas Nogueira. O Paradigma do Legislador Negativo e as Decisões Manipulativas com Efeitos Aditivos. Revista da PGBC - v. 5 - n. 2 - dez. 2011. Disponível em: < http://www.bcb.gov.br/pgbcb/122011/revista pgbc vol5 num2.pdf >. Acesso em 29 novembro de 2013;

KELSEN, Hans. Jurisdição constitucional. São Paulo: Martins Fontes, 1998.

MALFATI, Elena.; PANIZZA, Saulle.; ROMBOLI, Roberto. Giustizia Costituzionale. 4a Ed, Giappichelli Editore, Torino, 2013.

MALUF, André Luiz. Critérios objetivos para o porte de drogas: Omissão inconstitucional e sentenças aditivas. JOTA, 28 de novembro de 2016. Disponível em: < https://jota.info/artigos/criterios-objetivos-para-o-porte-de-drogas-26112016 > Acesso em 05 de maio de 2017.

Lei do Mandado de Injunção abre portas para sentenças aditivas. Conjur, julho de 2016. Disponível em: < http://www.conjur.com.br/2016-jul-25/andre-maluf-lei-mandado-injuncaoabre-portas-sentencas-aditivas $>$ Acesso em 20 de junho de 2017.

MALUF, André Luiz; SILVESTRE, Matheus Meott. Omissões Legislativas na Corte Equatoriana: um horizonte para o Brasil. Resumo Expandido apresentado no I Seminário de Jurisdição Constitucional e Justiça Dialógica na América Latina. Niterói: UFF, Junho, 2015.

MENDES, Gilmar Ferreira; BRANCO, Paulo Gustavo Gonet. Versão Digital. Curso de direito constitucional - 7. ed. rev. e atual. - São Paulo : Saraiva, 2012;

MORAES, Alexandre de. Escolha de ministros do STF precisa de mais participação de todos os poderes. Disponível em: < http://www.conjur.com.br/2014-jul-11/justica-comentada-escolha-stfenvolver-poderes> Acesso em: 11 de julho de 2014. 
NETO, Cláudio P. Souza; FILHO, Ademar Borges de Sousa. Raposa Serra do Sol expõe limites às sentenças aditivas. Disponível em: < http://www.conjur.com.br/2013-mar-07/raposa-serra-solexpoe-limites-producao-sentencas-aditivas >. Acesso em: 21 novembro de 2013;

NOBRE JÚNIOR, Edílson Pereira. Sentenças aditivas e o mito do legislador negativo. Revista de Direito Público, Porto Alegre, ano IV, n. 13, jul./ago./set.2006;

SOUZA NETO, Cláudio Pereira de. Teoria da constituição, democracia e igualdade. Disponível em <http://www.mundojuridico.adv.br/cgi-bin/upload/texto1129 (3).pdf> Acesso em: 21 de maio 2013;

ROMBOLI, Roberto. El Control de Constitucionalidad de las leyes in Italia. Disponível em: < http://www.juridicas.unam.mx/publica/librev/rev/trcons/cont/4/est/est7.pdf > Acesso em: 22 novembro de 2013;

PAIVA, Paulo Frederico. Decisões Manipulativas em controle de constitucionalidade e sua admissibilidade em material criminal. OBSERVATÓRIO DA JURISDIÇÃO CONSTITUCIONAL. Brasília: IDP, Ano 2, 2008/2009.

STRECK, Lenio Luiz. Jurisdição Constitucional e Decisão Jurídica. RT. 2013.

Enviado em: 07/05/2017

Aprovado em: 05/08/2017 